\title{
Di-n-butyl phthalate-induced phytotoxicity in Hordeum vulgare seedlings and subsequent antioxidant defense response
}

\author{
A. KUMARI and R. KAUR* \\ Department of Botanical and Environmental Sciences, Guru Nanak Dev University \\ Amritsar-143005, Punjab, India
}

\begin{abstract}
Di- $n$-butyl phthalate (DBP) is one of the frequently detected phthalates in environmental samples. The effects of phthalates are extensively studied in the animals but the effects on plants are scarce. Therefore, the present study is aimed to envisage the effects of DBP on the antioxidative defense system in Hordeum vulgare L. seedlings grown under laboratory conditions for $7 \mathrm{~d}$. The activities of different antioxidative enzymes were enhanced in the shoots. In the roots, the activity of guaiacol peroxidase increased and the catalase activity decreased initially but increased at higher DBP concentrations, whereas the activities of superoxide dismutase, ascorbate peroxidase, and glutathione reductase declined. Furthermore, the content of polyphenols elevated after exposure of seedlings to DBP. The possible reason for these responses of barley seedlings is the oxidative burst, i.e., enhanced production of reactive oxygen species, which were confirmed using confocal microscopy in terms of loss in plasma membrane integrity. DBP also disturbed the normal stomatal morphology of barley seedlings. The study may help to provide insights into the defense of crop plants against phthalate stress.
\end{abstract}

Additional key words: barley, confocal microscopy, plasma membrane integrity, SEM, stomata

\section{Introduction}

Phthalates have prodigious applications which are responsible for their ubiquity in different environmental samples. Phthalates are formed by the reaction of anhydrous phthalic acid with aliphatic alcohol. They are used as plasticizers for the production of cellulose, polyvinyl chloride, and synthetic rubber to impart them flexibility, toughness, and reduce hardness (Gao et al. 2019). Phthalates are also used in blood storage bags, intravenous catheters, toys, coatings of drugs, and personal care products, etc. (Benjamin et al. 2017). In the polymeric matrix, phthalates are incorporated via physical bonding rather than covalent bonding which enables their easy release into the environment (Gao et al. 2017). Several studies have reported the presence of considerable amounts of phthalates in agricultural soils. The main sources of phthalates are use of agricultural films, irrigation with waste water, effluents of industries, use of sewage sludge or biosolids for fertilization, use of pesticides, etc. (Cai et al. 2007, Weschler et al. 2008, Guo and Kannan 2012, Ma et al. 2013, Wang et al. 2013a,b). The increased greenhouse cultivation of edible plants has become a significant source of phthalate contamination (He et al. 2015). The concentrations of phthalates in plastic greenhouse soils or in agricultural film covered soils were reported to be several times greater than in other soils (Kong et al. 2012, Wang et al. 2012). Phthalate accumulation in edible plants affects their quality. For instance, the exposure to di (2-ethyl-hexyl) phthalate (DEHP) decreases the vitamin $\mathrm{C}$ content in the fruits of Capsicum sp. (Yin et al. 2002).

Some of the phthalates have been declared as 'Priority Environmental Pollutants' (Liao et al. 2010) and di-n-butyl phthalate (DBP) is one of them (Benjamin et al. 2017). In our previous studies, we observed that exposure of

Submitted 6 December 2018, last revision 7 April 2019, accepted 26 July 2019.

Abbreviations: ABA - abscisic acid; APX - ascorbate peroxidase; CAT - catalase; DBP - di- $n$-butyl phthalate; DEHP - di (2-ethyl-hexyl) phthalate; DEP - diethyl phthalate; EDTA - ethylenediaminetetraacetic acid; ETCs - electron transport complexes; GR -glutathione reductase; GSH - reduced glutathione; GSSG - oxidized glutathione; MDA - malondialdehyde; NBT - nitroblue tetrazolium; PBS phosphate buffer saline; PI - propidium iodide; POD - guaiacol peroxidase; PS - photosystem; ROS - reactive oxygen species; SEM - scanning electron microscopy; SOD - superoxide dismutase; UHPLC - ultra-high performance liquid chromatography.

Acknowledgments: The authors are thankful to the University Grants Commission, New Delhi, India for financial assistance provided under the National Fellowship for Higher Education scheme. We also thank Mr. Amandeep Walia and Mr. Kanwaljit Kumar for extending their help during confocal imaging and SEM analysis in the Department of Emerging Life Science, Guru Nanak Dev University, Amritsar. Thanks are due to Professor A.K. Thukral, Department of Botanical and Environmental Sciences, Guru Nanak Dev University Amritsar for help during statistical analysis.

* Corresponding author; e-mail: rajinder.botenv@gndu.ac.in 
barley to DBP significantly affected seed germination, growth, and some biochemical indices (Kumari and Kaur 2017, Kumari et al. 2019). DBP markedly enhanced the indicators of oxidative stress like malondialdehyde (MDA) and hydrogen peroxide $\left(\mathrm{H}_{2} \mathrm{O}_{2}\right)$. Furthermore, stimulation in the content of compatible solutes (proline, soluble sugars, and proteins) was observed in the shoots and roots of barley seedlings under DBP stress. Thus, the current work is an extension of our previous work to assess the potential of the antioxidative defense system against the oxidative stress induced by DBP.

\section{Materials and methods}

Plants and experimental setup: The seeds of Hordeum vulgare L. cv. VLB-118 were procured from Hill Agricultural Research and Extension Centre, Bajaura, Kullu, India. DBP (CAS: 84-74-2, purity: $99 \%$ ) was purchased from Himedia Laboratories (Mumbai, India) and all other chemicals used in the present study were of the analytical grade. DBP has a low water solubility, therefore, for the preparation of the stock solution, the method of Yin et al. (2003) was used. Barley seedlings were germinated as previously described by Kumari and Kaur (2017). The barley seeds were surface sterilized using $0.01 \%(\mathrm{~m} / \mathrm{v})$ mercuric chloride, presoaked in double distilled water and kept in Petri plates lined with Whatman No. 1 filter paper. The seeds were moistened periodically with different concentrations of DBP, viz. 0, $25,50,100,200,400,800$, and $1600 \mathrm{mg} \mathrm{dm}^{-3}$. The seeds were germinated under a $16-\mathrm{h}$ photoperiod, a temperature of $25 \pm 0.5{ }^{\circ} \mathrm{C}$, a relative humidity of $75-80 \%$, and an irradiance of $115 \mu \mathrm{mol} \mathrm{m} \mathrm{m}^{-2} \mathrm{~s}^{-1}$. The seedlings were harvested on the $7^{\text {th }}$ day and stored at $-80{ }^{\circ} \mathrm{C}$ till analyses.

\section{Extraction and estimation of antioxidative enzymes:} The shoots and roots of seedlings were separately pulverized in liquid nitrogen and homogenized in chilled 0.1 M potassium phosphate buffer ( $\mathrm{pH} 7.0$ ). The homogenate was centrifuged at $12000 \mathrm{~g}$ and $4{ }^{\circ} \mathrm{C}$ for $20 \mathrm{~min}$. The supernatant was collected and used for the analysis of activities of superoxide dismutase (SOD, EC 1.15.1.1), guaiacol peroxidase (POD, EC 1.11.1.7), catalase (CAT, EC 1.11.1.6), ascorbate peroxidase (APX, EC 1.11.1.11), and glutathione reductase (GR, EC 1.8.1.7). For the calculation of activities of antioxidative enzymes per protein unit, the content of the protein was determined using the standard method of the Bradford (1976).

The SOD activity was analyzed by the method of Kono et al. (1979). The reaction was initiated by the addition of sodium carbonate buffer $(50 \mathrm{mM}, \mathrm{pH} 10.2)$, nitroblue tetrazolium (NBT, $96 \mu \mathrm{M})$, Triton $X-100(0.6 \%$, v/v), hydroxylamine hydrochloride $(20 \mathrm{mM}, \mathrm{pH} 6.0)$ to enzyme extract. SOD activity was recorded as a decrease in absorbance at $540 \mathrm{~nm}$ of a complex formed by superoxide and NBT. One unit of SOD activity corresponded to the enzyme concentration required to inhibit the absorbance of formed chromogen at $540 \mathrm{~nm}$ by $50 \%$ in one min.

The POD activity was determined using the method of Putter (1974). For the estimation of POD activity, the reaction mixture was prepared using potassium phosphate buffer (0.1 M, pH 7.0), guaiacol (20 mM), $\mathrm{H}_{2} \mathrm{O}_{2}$ $(12.3 \mathrm{mM})$, and enzyme extract. The rate of formation of tetra-guaiacol was measured at $436 \mathrm{~nm}$ and enzymatic activity was calculated using coefficient of absorbance of $25.5 \mathrm{mM}^{-1} \mathrm{~cm}^{-1}$. One unit of POD activity corresponded to the amount of the enzyme catalyzing the formation of $1 \mathrm{~mol}$ of guaiacol dehydrogenation products per minute.

For determination of the CAT activity, the method given by Aebi (1984) was used. The reaction mixture was consisted of potassium phosphate buffer $(0.1 \mathrm{M}, \mathrm{pH} 7.0)$, $\mathrm{H}_{2} \mathrm{O}_{2}(150 \mathrm{mM})$, and enzyme extract. The decrease in absorbance was recorded at $240 \mathrm{~nm}$. The enzyme activity was determined using a coefficient of absorbance of $39.4 \mathrm{mM}^{-1} \mathrm{~cm}^{-1}$. One unit of CAT activity corresponded to the amount of the enzyme required for liberating $50 \%$ of oxygen from $\mathrm{H}_{2} \mathrm{O}_{2}$.

The APX activity was evaluated using the method of Nakano and Asada (1981). APX catalyzes $\mathrm{H}_{2} \mathrm{O}_{2}$ reduction by causing the oxidation of ascorbate. The reaction solution consisted of potassium phosphate buffer $(0.1 \mathrm{M}, \mathrm{pH} 7.0)$, ascorbate $(5 \mathrm{mM}), \mathrm{H}_{2} \mathrm{O}_{2}(0.5 \mathrm{mM})$, and enzyme extract. The decrease in absorbance was measured at $290 \mathrm{~nm}$ and the enzyme activity was calculated using a coefficient of absorbance of $2.8 \mathrm{mM}^{-1} \mathrm{~cm}^{-1}$. One unit corresponded to the amount of the enzyme required to oxidize $1 \mathrm{~mol}$ of ascorbate per minute.

The activity of GR was analyzed using the method of Carlberg and Mannervirk (1985). The reaction mixture contained potassium phosphate buffer $(50 \mathrm{mM}, \mathrm{pH} 7.6)$, ethylenediaminetetraacetic acid (EDTA, $3 \mathrm{mM}$ ), reduced nicotinamide adenine dinucleotide phosphate (NADPH, $0.1 \mathrm{mM}$ ), oxidized glutathione (GSSG, $1 \mathrm{mM}$ ), and enzyme extract. The absorbance was recorded at $340 \mathrm{~nm}$. The enzymatic activity was calculated using coefficient of absorbance of $6.22 \mathrm{mM}^{-1} \mathrm{~cm}^{-1}$. One unit corresponded to the amount of the enzyme required to oxidize $1 \mathrm{~mol}$ of NADPH per min.

Polyphenol profiling: The extracts of barley seedlings were prepared in methanol, filtered through $0.22 \mu \mathrm{m}$ filter membranes and then analyzed for different polyphenols using $130 \mathrm{MPa}$ Shimadzu (Kyoto, Japan) ultra-high performance liquid chromatography (UHPLC) system (NEXERA). UHPLC was coupled with $\mathrm{C}_{18}$ column $(150 \times 4.6 \mathrm{~mm}$ and pore size was $5 \mu \mathrm{m})$. During analysis, the binary mobile phase consisted of solvent A: $0.01 \%(\mathrm{~m} / \mathrm{v})$ acetic acid in water and solvent B: $100 \%$ methanol. The analysis of results was performed using $L a b$ Solutions software.

Confocal microscopy: For the determination of cell viability of DBP treated barley roots, method of Sasaki et al. (1997) was used with some modifications. The treated roots were rinsed with phosphate buffer saline (PBS) followed by staining with propidium iodide (PI) for $30 \mathrm{~min}$ in the dark and room temperature. After staining, the roots were washed in PBS for 3 - 5 times to remove the unbound stain particles from the root surface. The 
roots were scanned for confocal fluorescent imaging on Nikon AlR laser scanning confocal microscope (Nikon, Tokyo, Japan) coupled with built-in Nikon NIS Element $A R$ software for the acquisition of confocal images. He-Ne gas laser was used to excite electrons at a wavelength of $535 \mathrm{~nm}$ for PI

Scanning electron microscopy (SEM): For the study of DBP induced stomatal abnormalities, the samples were prepared using the method of Liu et al. (2000). For sample preparation, 4 - $5 \mathrm{~mm}$ segments of seedlings were cut followed by fixation in glutaraldehyde $(2.5 \%, \mathrm{~m} / \mathrm{v})$ for $24 \mathrm{~h}$. Then, the samples were dehydrated in graded ethanol series, mounted on the stubs with double sided tape, air-dried, and coated with silver. Abaxial surface of seedling was observed under SEM (Evo LS 10, Carl Zeiss, Oberkochen, Germany).

Statistical analysis: The results were analyzed for mean, standard error, and then two-way analysis of variance $(A N O V A)$ was used. The differences $(P \leq 0.05)$ among means were compared by the honestly significant difference (HSD) using Tukey's multiple comparison test.

\section{Results}

The results analyzed using ANOVA revealed that DBP exhibited statistically significant effects on the activities of antioxidative enzymes (Fig. 1, Table 1 Suppl.). The increasing concentrations of DBP exerted obvious effects on SOD activity of shoots and roots. In comparison to the control, the activities of SOD significantly increased by $41,51,55,35,39,33$, and $109 \%$ at $25,50,100,200$, 400,800 , and $1600 \mathrm{mg} \mathrm{dm}^{-3}$, respectively. In the roots, the SOD activity decreased and the decrease ranged from 48 to $68 \%$ with respect to the control.

A significant increase in the activity of POD was observed in shoots and roots of seedlings as compared to the control. In the shoots, a continuous increase in POD activity was observed, however, at higher concentrations $\left(400-800 \mathrm{mg} \mathrm{dm}^{-3}\right)$, the increase in POD activity was not dose-dependent, but remained higher than in control, followed by a decrease at $1600 \mathrm{mg} \mathrm{dm}^{-3}$. In the roots, POD activity increased in a dose-dependent manner except at $100-200 \mathrm{mg} \mathrm{dm}^{-3} \mathrm{DBP}$. The increase was 57, 81, 24, 22, 132,182 and $212 \%$ at $25,50,100,200,400,800$, and $1600 \mathrm{mg} \mathrm{dm}^{-3}$, respectively, as compared to the control.

In the shoots, there was a significant concentrationdependent increase in the activity of CAT (except at 50 and $200 \mathrm{mg} \mathrm{dm}^{-3}$ ), and a maximum increase in the activity was observed at $1600 \mathrm{mg} \mathrm{dm}^{-3}$. On the contrary, DBP exhibited a significant alteration in the activity of CAT either as an increase or decrease with respect to the control in the roots. The activities decreased at 25, 50, 100, $400 \mathrm{mg} \mathrm{dm}^{-3}$, thereafter elevated by 29,32 and $175 \%$ at 200,800 and $1600 \mathrm{mg} \mathrm{dm}^{-3}$.

The activity of APX increased significantly in the shoots under DBP stress at all the concentrations except at $1600 \mathrm{mg} \mathrm{dm}^{-3} \mathrm{DBP}$. The percent increase was dose- dependent at lower concentrations $\left(100-200 \mathrm{mg} \mathrm{dm}^{-3}\right)$. Thereafter, the activity started to decrease but the activity was steadily higher than in control. In the roots, initially the activity of APX increased and then a declining trend was observed. The decline ranged from 53 to $81 \%$ as compared to the control.

In the shoots, the activity of GR significantly increased over the control. The increase in GR activity was concentration-dependent except at 50-100 $\mathrm{mg} \mathrm{dm}^{-3}$. However, the activity of GR in the roots decreased significantly and the decrease was dose-dependent up to $200 \mathrm{mg} \mathrm{dm}^{-3}$ and then it increased but remained less than in the control.

The screening of polyphenols in methanolic extracts of barley seedlings is shown in Table 1. In the present study, the barley seedlings were analyzed for 11 polyphenols viz. gallic acid $\left(\mathrm{C}_{7} \mathrm{H}_{6} \mathrm{O}_{5}\right)$, caffeic acid $\left(\mathrm{C}_{9} \mathrm{H}_{8} \mathrm{O}_{4}\right)$, umbelliferone $\left(\mathrm{C}_{9} \mathrm{H}_{6} \mathrm{O}_{3}\right)$, coumaric acid $\left(\mathrm{C}_{9} \mathrm{H}_{8} \mathrm{O}_{3}\right)$, ellagic acid $\left(\mathrm{C}_{14} \mathrm{H}_{6} \mathrm{O}_{8}\right)$, quercetin $\left(\mathrm{C}_{15} \mathrm{H}_{10} \mathrm{O}_{7}\right)$, kaempferol $\left(\mathrm{C}_{15} \mathrm{H}_{10} \mathrm{O}_{6}\right)$, epicatechin $\left(\mathrm{C}_{15} \mathrm{H}_{14} \mathrm{O}_{6}\right)$, catechin $\left(\mathrm{C}_{15} \mathrm{H}_{14} \mathrm{O}_{6}\right)$, chlorogenic acid $\left(\mathrm{C}_{16} \mathrm{H}_{18} \mathrm{O}_{9}\right)$, and rutin $\left(\mathrm{C}_{27} \mathrm{H}_{30} \mathrm{O}_{16}\right)$. DBP remarkably altered the content of polyphenols in treated samples with respect to the control. The total polyphenol content decreased initially at $25 \mathrm{mg} \mathrm{dm}^{-3}$ followed by an increase up to 50 $800 \mathrm{mg} \mathrm{dm}^{-3}$ DBP. As concern contribution of individual polyphenols in total polyphenol content, catechin was dominated followed by caffeic acid, chlorogenic acid, epicatechin, kaempferol, umbelliferone, quercetin, ellagic acid, and coumaric acid.

The treated roots were examined for the loss of plasma membrane integrity using propidium iodide as a fluorescent probe. This fluorescent dye is impermeable to the intact cell and is used to differentiate between viable and nonviable cells. The low penetration of propidium iodide in the control showed that the cells were intact and viable, whereas the cells were damaged and became non-viable after exposure to higher concentrations of DBP (Fig. 2).

The dumbbell-shaped stomata of barley are shown on Fig. 3. In comparison to the control, the stomata of DBP treated barley seedlings were deformed. The treatment of DBP also initiated stomatal closure. Moreover, the length of stomata was also reduced, while the width was increased as compared to the control.

\section{Discussion}

The ROS is a collective term for radical oxygen species (i.e. superoxide, hydroxyl, alkyl, and peroxyl radical) and non-radical oxygen species (i.e., hydrogen peroxide, singlet oxygen, ozone, and hypochlorous acid) (Ahmad 2018). They are highly reactive and can mediate the oxidation of cell structure, biomolecules, as well as disturb cell integrity (Kanojia and Dijkwel 2018). Different metabolic processes often produce ROS under normal conditions, but the generation of ROS is observed to be significantly accelerated during abiotic or biotic stress. The cell organelles (chloroplast, mitochondria, and peroxisome) with high metabolic activity are the main sites of ROS generation. In chloroplast, there 
are three ways of ROS generation. The first one is the incomplete oxidation of water on the electron donor side of photosystem (PS) II and forms $\mathrm{H}_{2} \mathrm{O}_{2}$. The second site is within the electron transport chain, where the reduction of plastohydroquinone takes place which forms plastosemiquinone. Plastosemiquinone can interacts with
$\mathrm{O}_{2}$ to form superoxide radical $\left(\mathrm{O}_{2}{ }^{-}\right)$; (Khorobrykh et al. 2015). The third site is photosynthesis which involves the well-known electron transport complexes (ETCs) viz. PS I, PS II, and b6f complex (Kanojia and Dijkwel 2018). The direction of electron flow is from excited photosystem centers to NADP that forms NADPH. NADPH enters

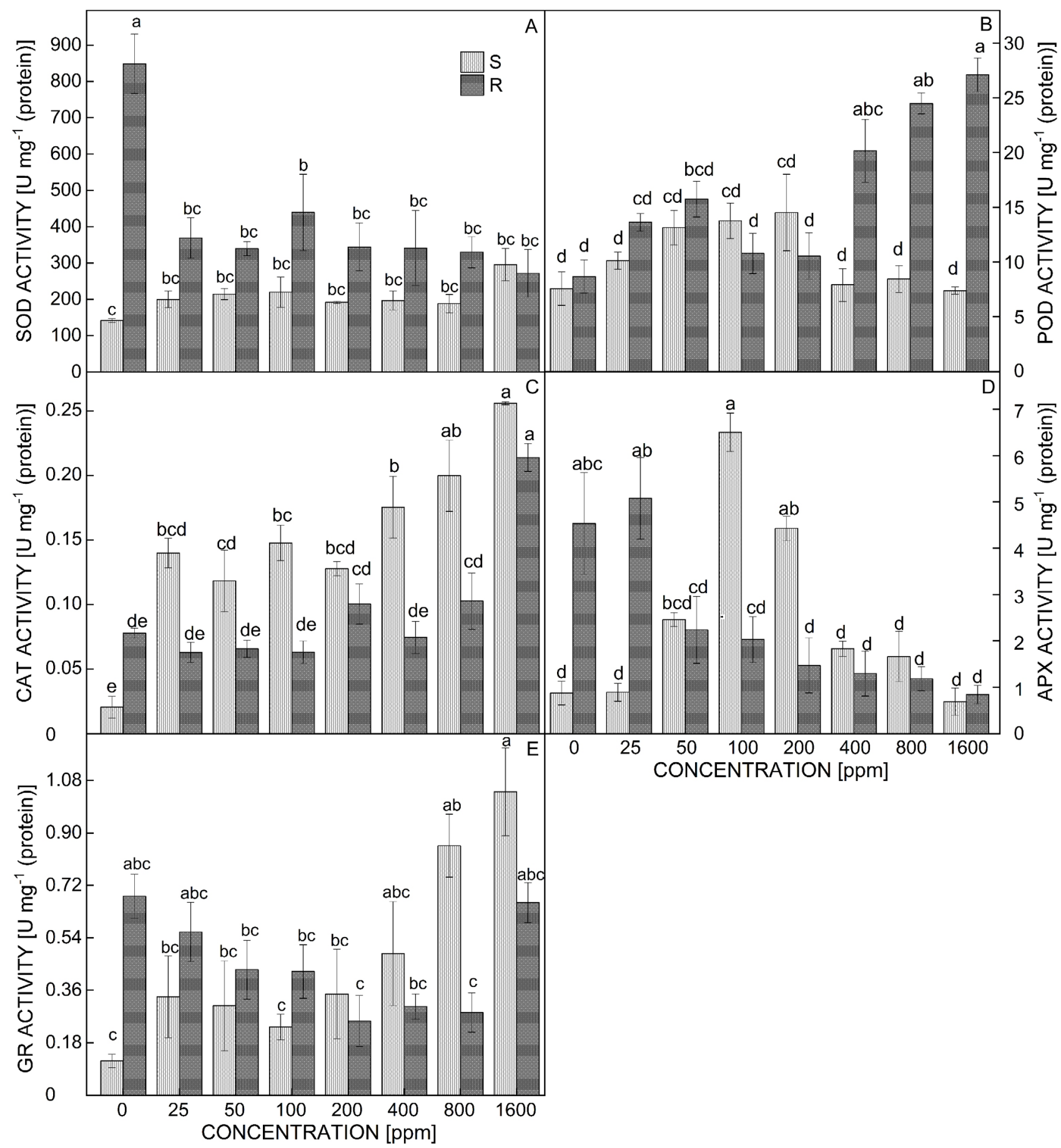

Fig. 1. Effect of di- $n$-butyl phthalate on superoxide dismutase (SOD, $A$ ), guaiacol peroxidase (POD, $B$ ), catalase (CAT, $C$ ), ascorbate peroxidase (APX, D), and glutathione reductase $(\mathrm{GR}, E)$ activities of shoots and roots of barley seedlings. Results are presented as means \pm SEs, $n=3$. Different letters indicate significantly different expression at a probability level of $5 \%$ as indicated by two-way ANOVA and honestly significant difference. 
Table 1. Effect of different di- $n$-butyl phthalate concentrations $\left[\mathrm{mg} \mathrm{dm}^{-3}\right]$ on content of polyphenols $\left[\mathrm{mg} \mathrm{g}^{-1}(\mathrm{f} . \mathrm{m}\right.$. $\left.)\right]$ in barley seedlings (ND - not detected).

\begin{tabular}{|c|c|c|c|c|c|c|c|c|c|c|}
\hline DBP & Caffeic acid & Chlorogenic acid & Quercetin & Kaempfer & Epicatech & Coumaric ac & Ellag & & Umbel & \\
\hline 0 & 0.108 & 0.083 & 0.011 & 0.024 & 0.071 & ND & ND & 1.030 & 0.015 & 1.342 \\
\hline 25 & 0.017 & 0.094 & 0.006 & 0.001 & 0.026 & 0.001 & 0.005 & 0.655 & 0.035 & 0.840 \\
\hline 50 & 0.031 & 0.048 & 0.026 & 0.028 & 0.001 & ND & ND & 1.215 & 0.043 & 1.392 \\
\hline 100 & 0.043 & 0.055 & 0.016 & 0.005 & 0.025 & ND & ND & 2.774 & 0.046 & 2.964 \\
\hline 200 & 0.039 & 0.050 & 0.006 & 0.019 & 0.023 & ND & ND & 2.405 & 0.018 & 2.560 \\
\hline 400 & 0.042 & 0.011 & 0.009 & 0.010 & 0.042 & ND & ND & 2.000 & 0.034 & 2.148 \\
\hline 800 & 0.085 & 0.001 & 0.017 & 0.041 & 0.041 & 0.001 & ND & 2.299 & 0.020 & 2.505 \\
\hline 1600 & 0.126 & 0.049 & 0.011 & 0.055 & 0.079 & ND & 0.006 & 0.150 & 0.038 & 0.514 \\
\hline
\end{tabular}

into the Calvin cycle and reduces $\mathrm{CO}_{2}$ which is the final electron acceptor. Whereas, during stress, the normal electron flow gets disturbed which limits $\mathrm{CO}_{2}$ assimilation and forms ${ }^{1} \mathrm{O}_{2}$ and $\mathrm{O}_{2}{ }^{-*}$.

Similarly, ROS generation takes place in mitochondria during ATP synthesis, and the main ROS generation ETCs are complex 1 and complex III (Sharma et al. 2012). Moreover, the mitochondrial enzymes, 1-galactono- $\gamma$ lactone dehydrogenase and aconitase are the key enzymes for the indirect and direct formation of $\mathrm{O}_{2}{ }^{--}$respectively (Kanojia and Dijkwel 2018). Beside chloroplasts and mitochondria, peroxisomes also produce ROS during stress and act as a major site for $\mathrm{H}_{2} \mathrm{O}_{2}$ generation (Smirnoff and Arnaud 2019). During stress, the mechanism behind switching high $\mathrm{H}_{2} \mathrm{O}_{2}$ generation is the low $\mathrm{CO}_{2}$ availability inside the plant leaves due to which ribulose- 1,5-bisphosphate carboxylase/oxylase catalyzes a competitive reaction. In the reaction, $\mathrm{O}_{2}$ is favored over $\mathrm{CO}_{2}$ which forms 2-phosphoglycolate (2-PG) instead of 3 -phosphoglycerate. To sustain the carbon assimilation, 2-PG is transported to peroxisome, where it is oxidized to form glyoxylate and $\mathrm{H}_{2} \mathrm{O}_{2}$ by glycolate oxidase (Flügel et al. 2017). Thus, to combat with the enhanced accumulation of ROS, plants have a defense grid that relies on endogenous enzymatic and non-enzymatic antioxidants. The enzymatic antioxidative defense system is an intricate, efficient, and includes enzymes like SOD, POD, CAT, APX, GR, etc. The non-enzymatic antioxidants are glutathione, ascorbate, carotenoids, tocopherols, polyphenolic compounds, etc.

Among the antioxidative enzymes, SOD acts as in a first-line of defense via catalyzing the dismutation of superoxide radical to $\mathrm{H}_{2} \mathrm{O}_{2}$ and $\mathrm{O}_{2}$ (Berwal and Ram
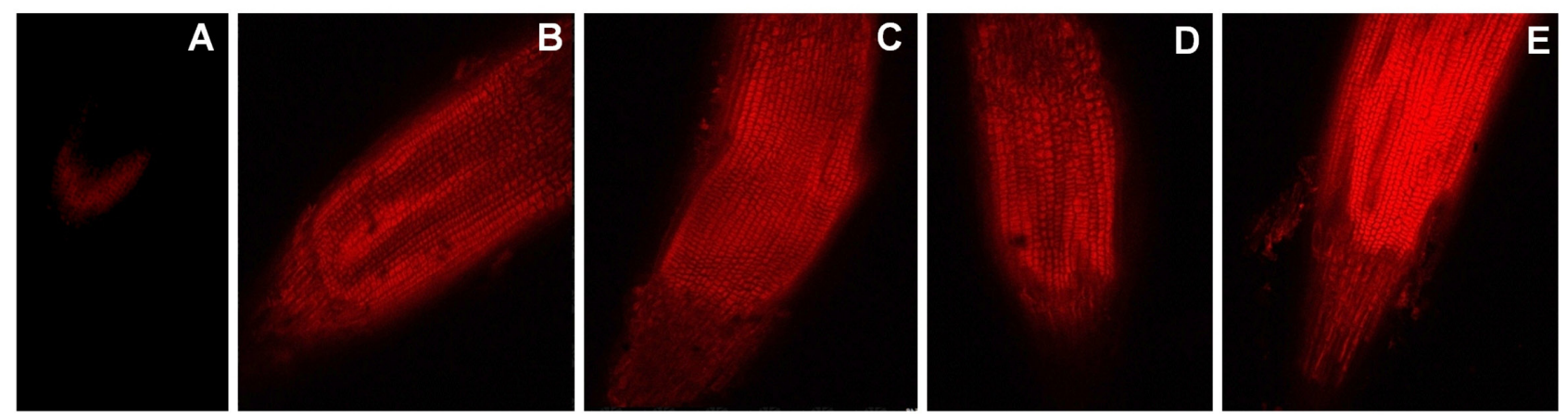

Fig. 2. Effect of di- $n$-butyl phthalate on cell viability in a control $(A), 25(B), 100(C), 400(D)$, and $1600 \mathrm{mg} \mathrm{dm}^{-3}(E)$ using confocal laser scanning microscopy.
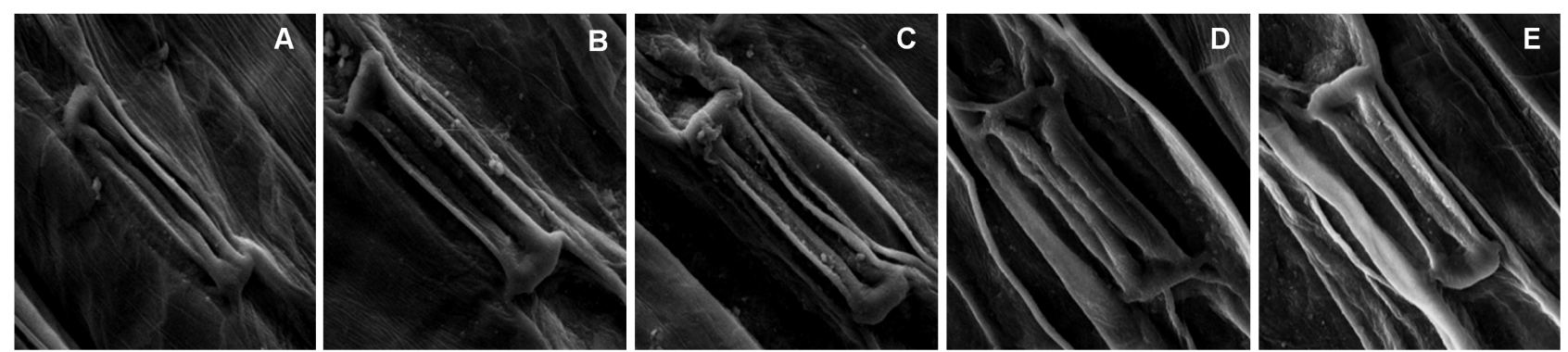

Fig 3. Effect of di- $n$-butyl phthalate on stomatal morphology at in a control $(A), 25(B), 100(C), 400(D)$, and $1600 \mathrm{mg} \mathrm{dm}^{-3}(E)$ using scanning electron microscopy. 
2018). In the present study, SOD was observed to increase in shoots, while it decreased in the roots under DBP stress. Cheng and Cheng (2012) reported similar results for the activity of SOD in Spirodela polyrhiza under the exposure of diethyl phthalate (DEP) for $7 \mathrm{~d}$ and the decline ranges from 22 to $28 \%$. They reported that the decrease in activity was due to the down-regulation of all isoenzymes of SOD. Ma et al. (2013) reported a decrease in the activity of $\mathrm{SOD}$ in Brassica chinensis under phthalate stress. The activity of SOD was reported to increase in the shoots and roots of mung bean seedlings exposed to $\operatorname{DBP}(5,20$ and $100 \mathrm{mg} \mathrm{kg}^{-1}$ for $72 \mathrm{~h}$ ), while a decline was observed at $500 \mathrm{mg} \mathrm{kg}^{-1}$ as compared to the control (Ma et al. 2014). In the same study, the effect of DEHP was also observed but the prominent effect was reported in DBP treated seedlings which can be attributed towards greater toxicity of DBP than other phthalates. The activity of SOD under the exposure of DBP in cucumber seedlings increases with increase in the DBP concentration and exposure duration, however, it declines at high concentrations of DBP (100$\left.200 \mathrm{mg} \mathrm{dm}^{-3}\right)$ and on the $7^{\text {th }}$ day, the observed decline is $47 \%$ (Zhang et al. 2015). In this work, the effects of DBP on SOD activity of shoots and roots could be due to the enhanced level of oxygen radical. The roots are in direct contact with contaminant that is why the effect on SOD activity was more apparent in roots than in shoots.

After the dismutation reaction of $\mathrm{O}_{2}{ }^{-*}$ catalyzed by $\mathrm{SOD}$, the accumulation of $\mathrm{H}_{2} \mathrm{O}_{2}$ is commonly observed. During the steady state, the content of $\mathrm{H}_{2} \mathrm{O}_{2}$ in chloroplast is usually up to $0.5 \mu \mathrm{M}$ and it is elevated to $1-1.5 \mu \mathrm{M}$ under stresses (Corpas et al. 2015). $\mathrm{H}_{2} \mathrm{O}_{2}$ is a moderately active ROS with 2 to $4 \mu$ s half-life. However, it is not that much damaging but can forms more reactive and damaging ROS like $\mathrm{OH}^{-}$via Haber-Weiss reaction (Czarnocka and Karpinski 2018). Therefore, there is a subsequent defense mechanism which involves the depletion of $\mathrm{H}_{2} \mathrm{O}_{2}$ before it enters to other reactions, and the key antioxidative enzymes are POD, CAT, and APX.

There was an increase in POD activity of shoots and roots under DBP stress. In DBP treated cucumber seedlings, the activity of POD significantly increased after $5 \mathrm{~d}$, while it is decreased in seedlings treated for $3 \mathrm{~d}$ (Zhang et al. 2015). The activity of POD increases significantly in cucumber seedlings under the exposure to 30 and $50 \mathrm{mg} \mathrm{dm}{ }^{-3}$ dimethyl phthalate for $7 \mathrm{~d}$ (Zhang et al. 2016). PODs are the only antioxidative enzymes which scavenge $\mathrm{H}_{2} \mathrm{O}_{2}$ in the apoplast, and have been classified as class III peroxidases by Welinder (1992). PODs (glycoproteins) are synthesized in the endoplasmic reticulum and transported via Golgi apparatus to extracellular spaces as well as to vacuoles (Jovanović et al. 2018). PODs catalyze the oxidation of phenolics, indoles, hydroquinones, and amines (Kaur 2013). The oxidation reaction catalyzed by PODs leads to the generation of phenoxyl radicals. These radicals are further polymerized or reduced by ascorbate (Jovanović et al. 2018).

Activity of CAT followed an increasing trend in the shoots and roots of barley seedlings under DBP exposure. In the various studies, the increase in CAT activity is reported to be correlated positively with $\mathrm{H}_{2} \mathrm{O}_{2}$ generation during stress (Choudhary et al. 2012, Li et al. 2013). Moreover, phthalates are also reported to enhance the production of $\mathrm{H}_{2} \mathrm{O}_{2}$ remarkably in plants (Bai et al. 2009, Zhang et al. 2014). CAT is an enzyme which scavenges $\mathrm{H}_{2} \mathrm{O}_{2}$ produced in peroxisomes under stressed conditions. In the present study, the enhanced activity of CAT is attributed to its indispensable role in the detoxification of $\mathrm{H}_{2} \mathrm{O}_{2}$. Furthermore, in our previous study, the content of $\mathrm{H}_{2} \mathrm{O}_{2}$ was also observed to enhance in the shoots and roots of barley seedlings under DBP stress (Kumari et al. 2019). The accumulation of $\mathrm{H}_{2} \mathrm{O}_{2}$ might be because of photorespiratory oxidation or $\beta$-oxidation induced by the exposure to DBP (Abbas et al. 2018).

In the shoots, APX activity increased initially and then decreased. However, in roots, it was recorded to increase at lower concentrations followed by a decrease at higher concentrations. Ma et al. (2014) observed similar results under the exposure to DEHP in the shoots and roots of mung bean seedlings. In Spirodela polyrhiza exposed to DEP, the activity of APX is reduced significantly at lower concentrations followed by an increase (Cheng and Cheng 2012). In wheat plants under DEHP exposure, the activity of APX increases as compared to the control (Gao et al. 2018). APX catalyzes the reduction of $\mathrm{H}_{2} \mathrm{O}_{2}$ using ascorbate as an electron donor; it plays an important role in the mitigation of intracellular ROS content (Abbas et al. 2018).

In the present study, GR activity was increased in the shoots, while declined in the roots. The activity of GR was also observed to increase under the exposure of DEP in Spirodela polyrhiza (Cheng and Cheng 2012). The activity of GR alters significantly under the exposure of other pollutants, e.g., Jiménez-Arias et al. (2019) observed an increase in the GR activity in tomato plants under menadione sodium bisulphite stress for $1 \mathrm{~d}$, and the maximum increase after $4 \mathrm{~d}$. The decline of GR activity was also observed in barley seedlings under salinity (Ma et al. 2019).

Polyphenols represent a class of secondary metabolites which are categorized as phenolic acids, flavonoids, stilbenes, and lignans. Polyphenols are non-enzymatic antioxidants and play various important roles in UV protection, pollen tube growth, antimicrobial activity, biotic and abiotic stress management, neutralization of free radicals, quenching of singlet oxygen, etc. (Dixon et al. 1995, Naczk 2004, Yadav et al. 2016). During stress, when ROS and free radicals are unable to be subdued by enzymatic antioxidants then, these are usually scavenged by polyphenols. The scavenging mechanisms based on the capacity of the phenol functional group to donate $\mathrm{H}$-atom or transfer single-electron from phenolic antioxidant to the free radical (Wright et al. 2001). The content of the phenolic compounds was reported to increase under $\mathrm{Cu}$ stress due to increased synthesis of shikimate dehydrogenase enzyme (Díaz et al. 2001). The polyphenols biosynthesis was also reported to increase in the crop plants under heavy metal stress (Michalak 2006). Thus, in the present study, an alteration in the content of polyphenols might be a part of coping strategy to deal with oxidative stress induced by DBP in barley seedlings. 
The confocal images of treated roots showed the considerable penetration of propidium iodide which may be attributed to the high ROS accumulation that might have led to the oxidative damages and finally cell death. The high accumulation of ROS can trigger programmed cell death (Foyer et al. 2005, Shi et al. 2015). The staining pattern of treated and untreated roots of barley seedlings clearly showed that exposure to DBP damaged the cell membrane via increasing the lipid peroxidation. Hence, the damaged cell membrane might have facilitated PI penetration into the cell which intercalated with DNA or RNA and formed a bright red fluorescent complex (Fig. 2).

The stomata are specialized tiny structures for controlling water and gas exchange. In this study, SEM micrographs of treated samples showed a reduction in size and initiation of stomatal closure. The morphological abnormalities in stomata were clearly visible in the treated samples, while the stomata in the control were compact and properly developed. Abscisic acid (ABA) accumulates during stress which is mainly responsible for the initiation of stomatal closure (Waraich et al. 2012). The high content of $\mathrm{H}_{2} \mathrm{O}_{2}$ was also reported as a possible reason for the initiation of stomatal closure (Yang et al. 2006). In this study, the accumulation of both $\mathrm{ABA}$ and $\mathrm{H}_{2} \mathrm{O}_{2}$ might have initiated the stomatal morphological abnormalities and closure in DBP treated samples.

In conclusion, it was observed that the exposure of barley seedlings to DBP caused significant modulations in the activities of antioxidative enzymes and the total polyphenolic content. The reason behind these responses might be the aggravated generation of ROS, which also caused a loss of the plasma membrane as well as disturbed normal stomatal morphology. Thus, the results of the present study will increase understanding crop plant responses to phthalate stress and the roles of enzymatic and non-enzymatic defense systems in the phthalate stress tolerance mechanism.

\section{References}

Abbas, G., Murtaza, B., Bibi, I., Shahid, M., Niazi, N., Khan, M., Amjad, M., Hussain, M.: Arsenic uptake, toxicity, detoxification, and speciation in plants: physiological, biochemical, and molecular aspects. - Int. J. Environ. Res. Public Health 15: 59, 2018.

Aebi, H. Catalase in vitro. - Methods Enzymol. 105: 121-126, 1984.

Ahmad, R.: Basics of free radicals and antioxidants. - In: Ahmad, R. (ed.): Free Radicals, Antioxidants and Diseases. Pp. 1-5. IntechOpen, London 2018.

Anjum, N.A., Ahmad, I., Mohmood, I., Pacheco, M., Duarte, A.C., Pereira, E., Umar, S., Ahmad, A., Khan, N.A., Iqbal M., Prasad, M.N.V.: Modulation of glutathione and its related enzymes in plants' responses to toxic metals and metalloids. Environ. exp. Bot. 75: 307-324, 2012.

Bai, R., Ma, F., Liang, D., Zhao, X.: Phthalic acid induces oxidative stress and alters the activity of some antioxidant enzymes in roots of Malus prunifolia. - J. chem. Ecol. 35: 488-494, 2009

Benjamin, S., Masai, E., Kamimura, N., Takahashi, K., Anderson, R.C., Faisal, P.A.: Phthalates impact human health: epidemiological evidences and plausible mechanism of action. - J. Hazard Mater. 340: 360-383, 2017.

Berwal, M., Ram, C.: Superoxide dismutase: a stable biochemical marker for abiotic stress tolerance in higher plants. - In: de Oliveira, A.B. (ed.): Abiotic and Biotic Stress in Plants. Pp. 1-10. IntechOpen, London 2018.

Bradford, M.M.: A rapid and sensitive method for the quantitation of microgram quantities of protein utilizing the principle of protein-dye binding. - Anal. Biochem. 72: 248-254, 1976.

Cai, Q.Y., Mo, C.H., Wu, Q.T., Zeng, Q.Y., Katsoyiannis, A.: Occurrence of organic contaminants in sewage sludges from eleven wastewater treatment plants, China. - Chemosphere 68: 1751-1762, 2007.

Carlberg, I., Mannervik, B. Glutathione reductase. - Methods Enzymol. 133: 484-490, 1985.

Cheng, L.J., Cheng, T.S.: Oxidative effects and metabolic changes following exposure of greater duckweed (Spirodela polyrhiza) to diethyl phthalate. - Aquat. Toxicol. 109: 166175,2012

Choudhary, R., Saroha, A.E., Swarnkar, P.L.: Effect of abscisic acid and hydrogen peroxide on antioxidant enzymes in Syzygium cumini plant. - J. Food Sci. Technol. 49: 649-652, 2012.

Corpas, F.J., Gupta, D.K., Palma, J.M.: Production sites of reactive oxygen species (ROS) in organelles from plant cells. - In: Gupta, D., Palma, J., Corpas, F.J. (ed.): Reactive Oxygen Species and Oxidative Damage in Plants under Stress. Pp. 1-22. Springer, Cham 2015.

Czarnocka, W., Karpiński, S.: Friend or foe? Reactive oxygen species production, scavenging and signaling in plant response to environmental stresses. - Free Radical Biol. Med. 122: 4-20, 2018.

Díaz, J., Bernal, A., Pomar, F., Merino, F.: Induction of shikimate dehydrogenase and peroxidase in pepper (Capsicum annuum L.) seedlings in response to copper stress and its relation to lignification. - Plant Sci. 161: 179-188, 2001.

Dixon, R.A., Paiva, N.L.: Stress-induced phenylpropanoid metabolism. - Plant Cell 7: 1085-1097, 1995.

Flügel, F., Timm, S., Arrivault, S., Florian, A., Stitt, M., Fernie, A.R., Bauwe, H.: The photorespiratory metabolite 2-phosphoglycolate regulates photosynthesis and starch accumulation in Arabidopsis. - Plant Cell 29: 2537-2551, 2017.

Foyer, C.H., Noctor, G.: Redox homeostasis and antioxidant signaling: a metabolic interface between stress perception and physiological responses. - Plant Cell 17: 1866-1875, 2005.

Gao, M., Dong, Y., Zhong, Z., Song, W., Qi, Y.: Growth and antioxidant defence responses of wheat to di- $n$-butyl phthalate and di(2-ethylhexyl) phthalate stress. - Chemosphere 172: 418-428, 2017.

Gao, M., Liu, Y., Dong, Y., Song, Z.: Photosynthetic and antioxidant response of wheat to di (2-ethylhexyl) phthalate (DEHP) contamination in the soil. - Chemosphere 209: 258267, 2018.

Gao, M., Liu, Y., Dong, Y., Song, Z.: Physiological responses of wheat planted in fluvo-aquic soils to di (2-ethylhexyl) and di- $n$-butyl phthalates. - Environ. Pollut. 244: 774-782, 2019.

Guo, Y., Kannan, K.: Challenges encountered in the analysis of phthalate esters in foodstuffs and other biological matrices. Anal. Bioanal. Chem. 404: 2539-2554, 2012.

He, L., Gielen, G., Bolan, N.S., Zhang, X., Qin, H., Huang, H., Wang, H.: Contamination and remediation of phthalic acid esters in agricultural soils in China: a review. - Agron. Sustain. Dev. 35: 519-534, 2015.

Jiménez-Arias, D., García-Machado, F.J., Morales-Sierra, S., Suárez, E., Pérez, J.A., Luis, J.C., Garrido-Orduña, C., 
Herrera, A.J., Valdés, F., Sandalio, L.M., Borges, A.A.: Menadione sodium bisulphite (MSB): beyond seed-soaking. Root pretreatment with MSB primes salt stress tolerance in tomato plants. - Environ. exp. Bot. 157: 161-170, 2019.

Jovanović, S.V., Kukavica, B., Vidović, M., Morina, F., Menckhoff, L.: Class III peroxidases: functions, localization and redox regulation of isoenzymes. - In: Gupta, D., Palma, J., Corpas, F.J. (ed.): Antioxidants and Antioxidant Enzymes in Higher Plants. Pp. 269-300. Springer, Cham 2018.

Kanojia, A., Dijkwel, P.P.: Abiotic stress responses are governed by reactive oxygen species and age. - Annu. Plant Rev. 1: $1-32,2018$.

Kaur, R.: Growth and biochemical and antimutagenic studies on Chlorophytum borivilianum Sant et Fernand. - Ph.D. Thesis, Department of Botanical and Environmental Sciences, Guru Nanak Dev University, Amritsar (Punjab), India, 2013.

Khorobrykh, S.A., Karonen, M., Tyystjärvi, E.: Experimental evidence suggesting that $\mathrm{H}_{2} \mathrm{O}_{2}$ is produced within the thylakoid membrane in a reaction between plastoquinol and singlet oxygen. - FEBS Lett. 589: 779-786, 2015.

Kong, S., Ji, Y., Liu, L., Chen, L., Zhao, X., Wang, J., Bai, Z., Sun, Z.: Diversities of phthalate esters in suburban agricultural soils and wasteland soil appeared with urbanization in China. - Environ. Pollut 170: 161-168, 2012.

Kono, Y., Takahashi, M.A., Asada, K.: Superoxide dismutases from kidney bean leaves. - Plant Cell Physiol. 20: 1229-1235, 1979

Kumari, A., Kaur, R.: Germination and early growth toxicity to barley seedlings (Hordeum vulgare L.) under di- $n$-butyl phthalate (DBP) stress. - J. Pharm. Sci. Res. 9: 2361-2366, 2017.

Kumari, A., Kaur, R., Sharma, R., Kaur, R.: Assessment of toxicological effects of di- $n$-butyl phthalate to a cereal crop (Hordeum vulgare L.). - J. Adv. Agric. Technol. 6: 20-26, 2019.

Li, Y., Zhang, X., Yang, Y., Duan, B.: Soil cadmium toxicity and nitrogen deposition differently affect growth and physiology in Toxicodendron vernicifluum seedlings. - Acta Physiol. Plant. 35: 529-540, 2013.

Liao, C.S., Chen, L.C., Chen, B.S., Lin, S.H.: Bioremediation of endocrine disruptor di-n-butyl phthalate ester by Deinococcus radiodurans and Pseudomonas stutzeri. - Chemosphere 78: 342-346, 2010.

Liu, D., Jiang, W., Qinghen, M., Liu, Q., Li, H., Gao, X., Guo, S.: Observation of root tips of garlic (Allium sativum L.) by electron microscopy after treatment with cadmium. - Isr. J. Plant Sci. 48: 289-295, 2000

Ma, T., Christie, P., Teng, Y., Luo, Y.: Rape (Brassica chinensis L.) seed germination, seedling growth, and physiology in soil polluted with di- $n$-butyl phthalate and bis (2-ethylhexyl) phthalate. - Environ. Sci. Pollut. Res. 20: 5289-5298, 2013.

Ma, Y., Wang, P., Wang, M., Sun, M., Gu, Z., Yang, R.: GABA mediates phenolic compounds accumulation and the antioxidant system enhancement in germinated hulless barley under $\mathrm{NaCl}$ stress. - Food Chem 270: 593-601, 2019.

Michalak, A.: Phenolic compounds and their antioxidant activity in plants growing under heavy metal stress. - Pol. J. environ. Stud. 15: 523-530, 2006.

Naczk, M., Shahidi, F. Extraction and analysis of phenolics in food. - J. Chromatogr. A 1054: 95-111, 2004.

Nakano, Y., Asada, K. Hydrogen peroxide is scavenged by ascorbate-specific peroxidase in spinach chloroplasts. - Plant Cell Physiol. 22: 867-880, 1981.

Putter, J. Peroxidases. - In: Bergmeyer, H.U. (ed.): Methods of Enzymatic Analysis. 2nd Ed. Vol. 2. Pp. 685-690. Academic Press, New York 1974.
Sasaki, M., Yamamoto, Y., Ma, J.F., Matsumoto, H.: Early events induced by aluminium stress in elongating cells of wheat root. - In: Ando, T., Fujita, K., Mae, T., Matsumoto, H., Mori, S., Sekiya, J. (ed.): Plant Nutrition for Sustainable Food Production and Environment. Pp. 439-444. Springer, Dordrecht 1997.

Sharma, P., Jha, A.B., Dubey, R.S., Pessarakli, M.: Reactive oxygen species, oxidative damage, and antioxidative defense mechanism in plants under stressful conditions. - J. Bot. 2012: 217037, 2012.

Shi, H., Jiang, C., Ye, T., Tan, D.X., Reiter, R.J., Zhang, H., Liu, R., Chan, Z.: Comparative physiological, metabolomic, and transcriptomic analyses reveal mechanisms of improved abiotic stress resistance in Bermudagrass [Cynodon dactylon (L). Pers.] by exogenous melatonin. - J. exp. Bot. 66: 681694, 2015.

Smirnoff, N., Arnaud, D.: Hydrogen peroxide metabolism and functions in plants. - New Phytol. 221: 1197-1214, 2019.

Ma, T.T., Christie, P., Luo, Y.M., Teng, Y.: Physiological and antioxidant responses of germinating mung bean seedlings to phthalate esters in soil. - Pedosphere 24: 107-115, 2014.

Wang, J., Luo, Y., Teng, Y., Ma, W., Christie, P., Li, Z.: Soil contamination by phthalate esters in Chinese intensive vegetable production systems with different modes of use of plastic film. - Environ. Pollut. 180: 265-273, 2013a

Wang, W., Zhang, Y., Wang, S., Fan, C. Q., Xu, H.: Distributions of phthalic esters carried by total suspended particulates in Nanjing, China. - Environ. Monitor. Assess. 184: 6789-6798, 2012.

Wang, X., Lin, Q., Wang, J., Lu, X., Wang, G.: Effect of wetland reclamation and tillage conversion on accumulation and distribution of phthalate esters residues in soils. - Ecol. Eng. 51: 10-15, 2013b.

Waraich, E.A., Ahmad, R., Halim, A., Aziz, T. Alleviation of temperature stress by nutrient management in crop plants. - J. Soil Sci. Plant Nutr. 12: 221-244, 2012.

Welinder, K.G.: Superfamily of plant, fungal and bacterial peroxidases. - Curr. Opin. Struct. Biol. 2: 388-393, 1992.

Weschler, C.J., Salthammer, T., Fromme, H.: Partitioning of phthalates among the gas phase, airborne particles and settled dust in indoor environments. - Atm. Environ. 42: 1449-1460, 2008.

Wright, J.S., Johnson, E.R., DiLabio, G.A. Predicting the activity of phenolic antioxidants: theoretical method, analysis of substituent effects, and application to major families of antioxidants. - J. amer. chem. Soc. 123: 1173-1183, 2001.

Yadav, P., Kaur, R., Kohli, S.K., Sirhindi, G., Bhardwaj, R.: Castasterone assisted accumulation of polyphenols and antioxidant to increase tolerance of $B$. juncea plants towards copper toxicity. - Cogent Food Agr. 2: 1276821, 2016.

Yang, S., Huang, C., Wu, Z., Hu, J., Li, T., Liu, S., Jia, W.: Stomatal movement in response to long distance-communicated signals initiated by heat shock in partial roots of Commelina communis L. - Science in China Series C 49: 18-25, 2006.

Yin, R., Lin, X.G., Wang, S.G., Zhang, H.Y.: Effect of DBP/ DEHP in vegetable planted soil on the quality of Capsicum fruit. - Chemosphere 50: 801-805, 2003.

Yin, R., Lin, X.G., Wang, S. G., Zhang, H.Y.: Influence of phthalic acid esters in vegetable garden soil on quality of capsicum fruit. - Agro Environ. Protocols 21: 1-4, 2002.

Zhang, Y., Du, N., Wang, L., Zhang, H., Zhao, J., Sun, G., Wang, P. Physical and chemical indices of cucumber seedling leaves under dibutyl phthalate stress. - Environ. Sci. Pollut. Res. 22: 3477-3488, 2015.

Zhang, Y., Wang, L., Du, N., Ma, G., Yang, A., Zhang, H., Wang, Z., Song, Q.: Effects of diethyl phthalate and di-(2- 
ethyl) hexylphthalate on the physiology and ultrastructure of cucumber seedlings. - Environ. Sci. Pollut. Res. 21: 10201028, 2014.

Zhang, Y., Zhang, H., Sun, X., Wang, L., Du, N., Tao, Y., Sun, G.,
Erinle, K.O., Wang, P., Zhou, C., Duan, S.: Effect of dimethyl phthalate (DMP) on germination, antioxidant system, and chloroplast ultrastructure in Cucumis sativus L. - Environ. Sci. Pollut. Res. 23: 1183-1192, 2016. 